A Discrete-Time Analysis of the Effects of More Prolonged Exposure to Neighborhood Poverty on the Risk of Smoking Initiation by Age 25

Nicole Kravitz-Wirtz, MPH, PhD ${ }^{\mathrm{a}, 1}$

${ }^{a}$ Department of Sociology, University of Washington, 211 Savery Hall, Box 353340, Seattle, WA 98195-3340

Corresponding author:Nicole Kravitz-Wirtz, Population Studies Center, University of Michigan, 426 Thompson Street, Rm. 2072, Ann Arbor, MI 48106-1248 (email: nicolekw@umich.edu)

${ }^{1}$ Present address: Population Studies Center, University of Michigan, 426 Thompson Street, Rm. 2072, Ann Arbor, Ml 48106-1248

(C) 2015. This manuscript version is made available under the Elsevier user license http://www.elsevier.com/open-access/userlicense/1.0/ 


\begin{abstract}
Evidence suggests that individuals who initiate smoking at younger ages are at increased risk for future tobacco dependence and continued use as well as for numerous smoking-attributable health problems. Identifying individual, household, and to a far lesser extent, contextual factors that predict early cigarette use has garnered considerable attention over the last several decades. However, the majority of scholarship in this area has been cross-sectional or conducted over relatively short windows of observation. Few studies have investigated the effects of more prolonged exposure to smoking-related risk factors, particularly neighborhood characteristics, from childhood through early adulthood. Using the 1970-2011 waves of the Panel Study of Income Dynamics merged with census data on respondents' neighborhoods, this study estimates a series of race-specific discrete-time marginal structural logit models for the risk of smoking initiation as a function of neighborhood poverty, as well as individual and household characteristics, from ages four through 25.Neighborhood selection bias is addressed using inverse-probability-of-treatment weights. Results indicate that more prolonged exposure to high (>20\%) as opposed to low (<10\%) poverty neighborhoods is associated with an increased risk of smoking onset by age 25 , although consistent with prior literature, this effect is only evident among white and not nonwhite youth and young adults.
\end{abstract}

KEYWORDS: neighborhood; poverty; smoking initiation; health disparities; life course; cumulative inequality 


\section{A DISCRETE-TIME ANALYSISOF THE EFFECTS OF MORE PROLONGED EXPOSURE TO NEIGHBORHOOD POVERTY ON THE RISK OF SMOKING INITIATIONBY AGE 25}

Smoking remains the leading preventable cause of disease, disability, and premature death in the United States (U.S.)(U.S. Department of Health and Human Services, 2010). Each year, approximately 443,000 individuals die from smoking-attributable diseases, and another 8.6 million people live with a serious illness caused by smoking or exposure to secondhand smoke(Centers for Disease Control and Prevention, 2011a, b). Prior research suggests that individuals who initiate smoking at younger ages are at increased risk for future tobacco dependence and continued use, as well as for ongoing health problems (Edelen et al., 2007; Ellickson et al., 2001; Everett et al., 1999; Lando et al., 1999).Identifying individual, household, and to a far lesser extent, contextual factors that predict early cigarette use has garnered considerable attention over the last several decades. However, the majority of scholarship in this area has been cross-sectional or conducted over relatively short windows of observation. Few studies have investigated the effects of more prolonged exposure to smoking-related risk factors from childhood through early adulthood. Those that do tend to focus on individual and household characteristics rather than characteristics of the broader neighborhood environment(Reardon et al., 2002). Resulting estimates, therefore, are unlikely to adequately account for exposure to multiplelevels of risk and are largely insensitive to both within and between group differences in the duration of such exposures.

This study uses the 1970 to 2011 waves of the Panel Study of Income Dynamics (PSID) merged with census data on respondents' neighborhoods to estimate a series ofrace-specific discrete-time marginal structural logit models for the risk of smoking initiation as a function of neighborhood poverty and individual and household characteristics from ages four through 25.Similar to the neighborhood effects literature more broadly, the few longitudinal studiesof smoking onset to examine risk factors at multiple levels of influence have been subject to complex and dynamic sources of bias related to the improper treatment of time-varying individual and household characteristics, as well as their role in processes of neighborhood selection. In contrast to more conventional regression-based techniques, this study employs inverse-probability-oftreatment (IPT) weights toadjust for suchmethodological difficulties. More specifically, the IPTweights account for dynamic residential selection processes without controlling away the effects of neighborhood poverty that may operate indirectly through the same individual- and household-level covariates that have been associated with residential mobility (and subsequent smoking initiation). Results from these analyses indicate 
that longer-term residence in an impoverished neighborhood influences smoking behavior above and beyond,as well as in conjunction with individual and household characteristics. In particular, more prolonged exposure to high (>20\%) as opposed to low (<10\%) poverty neighborhoodsis associated with an increased risk of smoking onset by age 25; although consistent with prior literature, this effect is only evident among white and not nonwhite respondents.

\section{THEORETICAL BACKGROUND}

Research examining the health effects of neighborhood characteristics, particularly concentrated poverty and other forms of socioeconomic disadvantage, has surged in recent decades. Numerous studies have linked adverse residential conditions to premature death (Doubeni et al., 2012), poor self-rated health (Tomey et al., 2013; Yen \& Kaplan, 1999), depression and other mental health problems (Ahern \& Galea, 2011; Beard et al., 2009; Cutrona et al., 2006; Gapen et al., 2011), health-risk behaviors such as poor diet and physical inactivity (Gordon-Larsen et al., 2006; Jackson et al., 2010), and related chronic conditions such as obesity, diabetes, cardiovascular disease, and certain cancers (Auchincloss et al., 2008; Ana V. Diez Roux et al., 2001; Ana V. Diez Roux et al., 1997; Mujahid et al., 2008; Papas et al., 2007), net of individual- and household-level factors. There is also a sizable body of literature on the relationship between neighborhoods and substance use, including smoking behavior.Early findings from this work suggested that residing in more deprived neighborhoods was associated with an increased risk of tobacco use(Chaix et al., 2004; Chuang et al., 2005; A. V. Diez Roux et al., 2003a; Kleinschmidt et al., 1995; Reijneveld, 1998; Shohaimi et al., 2003; Tseng et al., 2001). More recent studies, however, reveal a more nuanced landscape in which the effects of neighborhood characteristics on tobacco use differacross age and racial groups.

Among adolescents and young adults aged 12 to 21, for example, Lee and Cubbin(2002)find no associations between low neighborhood socioeconomic status or high neighborhood social disorganization and smoking behavior, whereas Ennett and colleagues (1997)document higher rates of cigarette use among children in elementary schools located in neighborhoods perceived as lessrather than moresocially disadvantaged.Moreover, other scholars have suggested that for some young people, the effects of neighborhood poverty on smoking uptake may not manifest until the transition from adolescence to young adulthood when individual and familial factors that had previously helped to buffer the impacts of such residential adversity are removed (or at least considerably altered) in conjunction with the often inevitable restructuring of roles and relationships during this stage of the life course(Graber \& Gunn, 1999; Hammond, 
2005). With respect to differences by race, nonwhites generally report considerably lower levels of initial substance use, including cigarette smoking, as well as lower uptake rates over time, compared to their white counterparts (Chen \& Jacobson, 2012). Several studies furtherpoint torace-specificeffects of neighborhood poverty on smokinginitiation. For example, Nowlin and Colder (2007)find that higher levels of neighborhood poverty are associated with increased smoking for white but not black youth. Other scholars have also found that living in a predominantly black neighborhood protects black but not white adolescents from cigarette use, whereas living in a predominantly white neighborhood is associated with more cigarette use among both black and white youth, especially in more impoverishedneighborhoods (Xue et al., 2007).

To a certain extent then, such findings challenge expectations based on the theoretical frameworks commonly used to help explain neighborhood effects on health and health behaviors. The social isolation paradigm, for example, contends that macroeconomic changes related to the 1970s-era deindustrialization of central cities resulted in the systematic separation (often in both physical and social space) of low-income residents from middle- and upper-income families whose presence in the same urban neighborhoods had previously served to validate mainstream, often salutatorynorms, as well as helped to attract and sustain the basic institutions of the area (Small, 2006; Small \& Newman, 2001; Wilson, 1987). In terms of its influence on health behaviors such as cigarette smoking, social isolation is often invoked in conjunction with theories of collective socialization and place-based epidemic or contagion processes(Jencks \& Mayer, 1990). That is, the relative isolation of residents (particularly younger residents) of impoverished neighborhoods from role models who have achieved a degree of social and economic security through mainstream channels increases the likelihood that the socialization of low-income children, youth, and young adults will include formative interactions with peers whotend to be unemployed and not in school (and therefore more likely to be available and visible in the neighborhood), as well as more likely to engage in deviant or health compromising behaviors(Harding, 2009). In more impoverished areas, therefore, cigarette smoking may not only be more prevalent, but also particularly salient and respected, and therefore more likely to spread through collective processes of exposure to and social learning via qualitatively distinct, influential others(Miles, 2006). Moreover, because middle- and upper-income families help attract and sustain basic (often salutary) institutions, such as churches, grocery stores, and recreational centers, their relative absence means that impoverished neighborhoods are disproportionately likely to be served by businesses, 
including convenience and other small stores, in which tobacco products are more prominent, more heavily marketed, and more accessible(John et al., 2009; Siahpush et al., 2010).

Similarly, extant theories of social (dis)organization, or what have been re-conceptualizedin terms ofsocial capital and more recently, as collective efficacy and informal social control,suggest that differences across neighborhoods in mutual trust as well as shared expectations and capacities for prosocial action (a collective sense of 'we') are associated with variations in rates of crime and other deviant behaviors. That is, residents of more advantaged areas with higher levels of collective efficacy are more likely to feel empowered to intervene and to enforce salutary norms and behaviors (Sampson et al., 1997). In such neighborhoods,residentsare more likely to know each other, share information about young people's behavior, monitor spontaneous hang outs among youth, and feel justified stepping in to actively discourage tobacco use in both private and public spaces and among both known and unknownneighbors.Moreover, at the institutional level, differences in collective efficacy across more or less deprived neighborhoods may influence residents' willingness and capacity to mobilize and extract resources, for example, to advocate for the passage of a local ordinance to restrict smoking in public places or to use zoning restrictions to prevent tobacco advertising and tobacco outlets in their neighborhoods.

Finally, theories related to the quality of and access to resources in the institutional and physical (or "built") environments suggest that such characteristics constitute so-called opportunity structureswhich may promote or damage health either directly or indirectly through the possibilities they provide for people to make and maintain healthy choices and live healthy lives (Macintyre et al., 2002; Miles, 2006). As already mentioned in relation to both social isolation and collective efficacy, neighborhoods vary according to their levels of tobacco advertising and availability, the extent to which local institutions and public places encourage cigarette smoking by permitting it on their premises and selling smoking-related products, or whether they visibly discourage it by prohibiting smoking and having signage to that effect, raising awareness about the hazards of smoking, having signs indicating that they do not sell to minors, and individuals as well as organizational practices responsible for enforcing such policies (Frohlich et al., 2002; Miles, 2006). More socially advantaged neighborhoods tend to have more anti-smoking structural aspects, whereas residents of impoverished neighborhoods are disproportionately likely to encounter institutional and built environments which encourage, or at least do not actively discourage, tobacco use(Frohlich et al., 2002). 
In theoretical terms, therefore, the relationship between neighborhood disadvantage and smoking appears straightforward and deleterious. However, as discussed above, many empirical studies report substantially higher prevalence of substance use, particularly cigarette smoking, among white compared to Hispanic, and especially African American,children, adolescents, and young adults despite these latter groups' greater exposure to individual, household, and neighborhood-level risk factors, including neighborhood poverty (A. V. Diez Roux et al., 2003b; Gardiner, 2001; Griesler \& Kandel, 1998; Tseng et al., 2001). Explanations for such racially disparate patterns have been largely speculative, although a few rationales have gained traction in the empirical literature.Central among these are the notions that white youth are more susceptible to pro-smoking peer pressure and smoking-related status attainment processes (e.g., the belief that smoking improves one's social standing) (Unger et al., 2001), whilenonwhite, and black youth in particular, are more likely to encounter religious and parental disapproval of smoking (Ellickson et al., 2004; Flay et al., 1994), allof which are posited to mediate the relationship between neighborhood povertyand smoking initiation/use. On the whole, though, it remainslargely unclear why cigarette smoking diverges so considerably from other health compromising behaviors for which neighborhood-level risk factors tend to have universally deleterious impacts and to which nonwhite populationsare disproportionately exposed.

However, as mentioned at the outset of this article, largely absent from discussions of neighborhood effects on smoking is the element of time. Not only are nonwhites more likely to live in poorareas than whites, but prior research documents that the proportion of nonwhites who reside in impoverished neighborhoods for repeated or prolonged periods of time is greater than the proportion who do so at any one point in time(Sharkey, 2013; South \& Crowder, 1998; Timberlake, 2007).Conversely, whites are more likely to experience episodic as opposed to sustained residence in deprivedneighborhoods (Quillian, 2003). The majority of research on neighborhoods and smoking, though, has relied on cross-sectional data(Chen \& Jacobson, 2012). This not only glosses over potential differences in trajectories of smoking behavior, but more importantly for purposes of the current study, it implicitly ignores how the duration of exposure to neighborhood-level risk and protective factors may moderate effects on smoking onset or race-specific patternstherein.To address this limitation, this study focuses explicitly on how more prolonged exposure to varying levels of neighborhood poverty affects the risk of smoking initiation among white and nonwhite, predominantly African American, youth and young adults. Given the potential for point-in-time measures of 
the neighborhood environmentto underestimate exposure among nonwhites but overstate exposure among whites, a central aim of this study is to assess how including a duration-sensitive measure of neighborhood poverty influencessmoking initiation risk by race, and in particular, whether a neighborhood effect emergesamong nonwhite respondents when the length of exposure to neighborhood poverty is considered.

\section{DATA ANDMETHODS}

Data for this study are drawn from the 1970 to 2011 waves of the Panel Study of Income Dynamics (PSID), produced and distributed by the University of Michigan's Institute for Social Research and funded by the National Institutes of Health and the National Science Foundation. The PSID is a large, longitudinal survey of US residents and their families conducted annually between 1968 and 1997 and every two years thereafter. The PSID has several strengths that make it particularly well-suited to the objectives of this study. First, the dataset contains an oversample of low-income families, as well as a wealth of information on a variety of smoking-related individual- and household-level risk and protective factors. Second, the longitudinal design of the PSID makes it possible to adjust for the temporal sequencing and compounding influence of individual, household, and neighborhood characteristicsacross time. Third, the residential location of individual respondents at each interview can be linked to their corresponding census tract identifiers using the PSID's supplemental, restricted-use Geospatial Match Files. These identifiers make it possible to characterize neighborhood poverty for prolonged intervals, as well as to account for the potential mobility of PSID respondents into and out of more or less impoverished areas. Procedures were approved by [XXXX] and through contractual agreement with $[\mathrm{XXXX}]$.

\subsection{SAMPLESELECTION}

The analytic sample for this study is restricted to the 2,121PSID respondentswho were born in 1966or later and who were present in the panel as a household head or partner (legal spouse or cohabiter) at least once between 1999 and 2011 when a set of questions about current and/or past smoking behavior were asked. Respondents who were present but never responded to any questions about smoking behavior were also excluded.Analyses utilize information on remainingrespondents that had been collected at every survey wave from age four (calendar years 1970 and later) until they first became nonresponse, began smoking, or they reached the administrative end of follow-up, defined as either age 25 or calendar year 2010. Neighborhood effect estimatesare based on 27,488 person-years of observation,reflecting the period from one year post-baseline, when respondents were age five,until they began smoking or were otherwise 
censored: 17,303 person-years from respondents classified as white and 10,185 person-years from those classified as nonwhite.

\subsection{DEPENDENT VARIABLE}

The dependent variable is whether an individual began smoking by age 25 . Beginning in 1999, PSID respondents who were classified as either a household head or the spouse of a household head were asked, "Do you smoke cigarettes?" If they answered no, they were also asked, "Did you ever smoke cigarettes?"If

they answered no again, they were coded as nonsmokers (0). However, if they answered yes to either of the above questions, respondents were subsequently asked, "How old were you when you first smoked cigarettes regularly?" Responses to this question were recorded in whole-year increments. Because this same question was asked at multiple survey waves (1999, 2001, 2003, 2005, 2007, 2009 and 2011), there may be discrepancies in individual responses across waves. If a respondent reported more than one age at smoking onset, the smallest (youngest) modal response was used.

\subsection{MAIN INDEPENDENT VARIABLE}

Similar to most prior research in this area, census tracts are used to approximate neighborhood boundaries. Although there are well-known limitations to this operational definition (Matthews, 2011), there is broad consensus that census data at the tract level not only provide convenient access to considerable information over extensive time periods, but they also serve as a reasonable proxy for, or are at least highly correlated with, the "true" causally relevant definition of a neighborhood (Crowder \& Downey, 2010; Ana V. Diez Roux \& Mair, 2010; Sampson, 2013; Sharkey \& Faber, 2014). Information on census tracts in 1970, 1980, 1990, 2000, and 2010 comes from the Neighborhood Change Database in which data for all five decades has been normalized to 2010 tract boundaries and can therefore be compared across years without having to adjust for potential changes in boundary definitions over time. Data for intercensal years are estimatedusing linear interpolation.

Neighborhood poverty is operationalized as a three-level, time-varying variable based on the poverty rate of the census tract in which a respondent resided at each survey wave. Consistent with the cutoffs used in prior literature (Wodtke, 2013), tracts with less than a 10 percent poverty rate are coded as "low-poverty neighborhoods (1)"; tracts with poverty rates between 10 and 20 percent are coded as "moderate-poverty neighborhoods (2)"; while tracts with greater than a 20 percent poverty rate are coded as "high-poverty neighborhoods (3)". To assess the duration of time a respondent was exposed to each level of neighborhood 
poverty, a three-category dummy-codedmeasure of cumulative, or duration-sensitive,exposure was generated as the proportion of time that respondents lived in low-, moderate-, and/or high-poverty neighborhoods from one year post-baseline (age five) throughthe survey wave at which they were censored (i.e., became nonresponse, began smoking, or reached the administrative end of follow-up). For example, if the data are organized in long form (person-years) and a respondent spent ages five and six in low-poverty neighborhoods and age seven in a moderate-poverty neighborhood, they would be coded "1" on the lowpoverty dummy and "0" on both the moderate- and high-poverty dummies at age five. The same would be true at age six. However, at age seven, they would be coded "0.667"on the low-poverty dummy, "0.333"on the moderate-poverty dummy, and "0"on the high-poverty dummy to reflect the proportion of time they had resided in each of the different levels of neighborhood poverty by age seven (two of three years in lowpoverty, one of three years in moderate-poverty, and zero of the three years in high-poverty neighborhoods).

\subsection{COVARIATES}

A large number of individual- and household-level variables are included in analyses as either timeinvariant or time-varying. Time-invariant covariates include a respondent's race ( $1=$ nonwhite; $0=$ white), gender ( $1=$ female; $0=$ male), birthweight ( $1=$ less than 88 ounces; $0=88$ ounces or more), mother's age at birth, mother's marital status at birth (1=unmarried; $0=$ married), and household head's educational attainment at age four, the start of follow-up in this study (1=less than high school; 2=high school graduate; 3=at least some college). Time-varying covariates, measured for every respondent at each wave between ages four and 25, include household head's marital status (1=unmarried; $0=$ married), employment status (1=unemployed; $0=e m p l o y e d)$, and work hours, as well as family size, homeownership (1=does not own home; $0=0$ owns home), public assistance receipt ( $1=y e s ; 0=$ no), and total household income, standardized using the Consumer Price Index to 1985 dollars.

\subsection{Statistical ANAlysis}

This study employs a series of race-specific discrete-time marginal structural logit models based on all person-year observations in which the parameters are estimated using IPT weights.This estimation technique has been described in more detail elsewhere (Wodtke, 2013). In brief, the IPT weights are used to mimic random assignment of exposure to different levels of neighborhood poverty based on individual and household characteristics, essentially adjusting for neighborhoodselection bias by generating a weighted "pseudo-population" to which the discrete-time marginal structural logit models are subsequently fit. The 
overall process proceeds in two steps. First, ordinal logistic regression isused to estimate each respondent's probability of being exposed to low-, moderate-, and high-poverty neighborhoods (contrary to what is actually observedfor two of the three levels of poverty) at each survey wave (year), conditional on their level of neighborhood poverty in the prior year, baseline or time-invariant covariates (including neighborhood poverty at age four), and both prior and concurrent time-varying individual- and household-level covariates. Respondents are then assigned a series of IPT weights based on the inverse (or reciprocal) of the probability that they were exposed to their actual (observed) level of neighborhood poverty at each wave of follow-up. In this way, proportionally more (or less) weight is given to those respondents whose prior timevarying individual- and household-level covariates are underrepresented (or overrepresented) in the neighborhood to which they were actually exposed at each wave. That is, the IPT weights ensure that the values of all covariates included in their construction are balanced in expectation across the three levels of neighborhood poverty at each wave.

In practice, IPT weights can be highly variable. To increase efficiency and obtain narrower confidence intervals around the subsequent neighborhood effect estimate, the IPT weights for each respondent at each wave are stabilized by multiplying each one by the same probability as was used to generate it, except only time-invariant covariates and prior year neighborhood conditions are included as regressors (i.e., timevarying covariates are excluded)(Robins, 2000; Robins et al., 2000). These probabilities of exposure that condition on only time-invariant predictors become the numerators ofthe original IPT weights described above. The result are stabilized IPT weights for each respondent at each wave that tend to be centered around one and not highly variable. These are then multiplied together across waves to generate a single value representing each respondent's overall contribution to the pseudo-population.

In the second step of the analytical process, the IPT-weighted pseudo-population is used to fit a conventional discrete-time logit model for the risk of smoking onset in which the dummy-coded measure of exposure to low-, moderate-, and high-poverty neighborhoods is included as the main explanatory variable, along with a quadratic function of age.Because the time-invariant covariates are included in the logistic regression models used to calculate both the numerator and the denominator of the stabilized IPT weights, they must still be included as control variables in the final discrete-time model. Time-varying covariates are not included, however. The impact of these variables as potential confounders influencing both selection into neighborhoods and future smoking onset is already accounted for through the weighting process, while their 
role as potential mediators of the neighborhood-smoking relationship, although not examined directly,still contributes to the overall neighborhood effect. All models, including those used to generate the stabilized IPT weights, are estimated separately for nonwhite and white respondents because prior research suggests that processes of smoking initiation differ by race (Ellickson et al., 2004; Flay et al., 1994; Unger et al., 2001; White et al., 2004).Huber-White robust standard errors are used to account for the clustering of respondents within the same PSID households (Robins et al., 2000; Wodtke et al., 2011).

To be unbiased and consistent, parameters estimated using the IPT weights require several key assumptions, including no unmeasured confounding, no model misspecification, and positivity (Robins et al., 2000; Wodtke, 2013). Although this study adjusts for a wide array of among the most common predictors of both neighborhood selection and smoking onset, there is still the possibility that factors not measured in the PSID including, most obviously, psychosocial characteristics, could upwardly bias the neighborhood effect estimate. Incorrectly specified models for selection into neighborhoods characterized by varying levels of poverty could also bias the neighborhood effect estimate. However, other scholars utilizing the PSID and similar covariates have demonstrated that neighborhood effect estimates are relatively robust to a variety of model specifications (Wodtke, 2013). Finally, and perhaps most glaring in light of persistent racial-spatial inequalities, is the assumption of positivity or "overlap", meaning that both nonwhites and whites must have a non-zero probability of being exposed to every level of neighborhood poverty across all levels and combinations of measured covariates.Violations of the positivity assumption can result in weights that are unstable and sensitive to the presence of rare combinations of covariates. This analysis attempts to mitigate this problem in part by stratifying the models by race. Moreover, descriptive analyses show non-zero probabilities of exposure to all levels of neighborhood poverty for both nonwhite and white respondents. As just described,though, positivity assumes a non-zero probability of exposure to every level of neighborhood poverty for all combinations of covariates, not just race in isolation. As more covariates are included, data become sparse and the likelihood of non-positivity naturally increases. However, such zero probabilities are more likely to be random rather than structural in nature.On the whole, the stabilized IPT weights for both racial groups have means close to one and small standard deviations, suggesting that the presence of rare combinations of covariates did not exert overt influence on the results. 


\subsection{MISSING DATA}

Of the 27,488 person-years of data examined in this study, most independent variables were only missing about one percent of cases. Characteristics of respondents' mothers, including her marital status and age at respondents' birth, as well as respondents' birthweight and household head's educational attainment at baseline, had slightly higher rates of missingness, usually between three and 10 percent.However, because the Census Bureau did not fully tract the US until 1990, tract level data on neighborhood poverty was unavailable in approximately 20 percent of cases, largelyduring the 1970 s and 1980s. Missing data on all independent variables wasmultiply imputed using the two-fold fully conditional specification algorithm in STATA v.13.1 (Welch et al., 2013). Whereas conventional multiple imputation methods ignore the longitudinal and dynamic structure of panel data and are difficult to implement in large databases with many respondents and long periods of follow-up, the two-fold approach imputes missing values using chained equations at each time point conditional on information at the same time point and user-specified adjacent time points (Welch et al., 2013). This study employs concurrent information plus or minus the one year adjacent to any missing values for the multiple imputation. Although the degree of missingness for neighborhood poverty, in particular, was non-negligible, an extensive set of associated individual- and household-level characteristics plus census data at immediately adjacent time points were included in the imputation algorithm. Moreover, employing county-level poverty rates instead of multiply imputed (tract-level) values produced results that were substantively unchanged (results available upon request).

\section{RESULTS}

\subsection{SAMPLECHARACTERISTICS}

Tables 1 and 2 display descriptive statistics for the time-invariant and time-varying sample characteristics, respectively, among nonwhite and white respondents. As shown, there are considerable racial differences across most variables of interest. For example, nonwhite respondents - approximately 95 percent of whom are African American - are over six times as likely to be born to an unmarried mother, more than twice as likely to be low birthweight, and about three times as likely at age four to live in a household in which the head had less than a high school education compared to white respondents (Table 1).

[TABLE 1 HERE] 
To provide an indication of the temporal patterns of exposure to time-varying individual-, household-, and neighborhood-level risk factors, Table 2 reports aggregatestatistics by race at three different cross-sections: age four, age 12, and age 17. Although the general pattern appears positive over time for both nonwhite and white respondents - that is, the percentage of respondents exposed to smoking-related risk factors decreases, on average, betweenthe age four andage 17 time points - striking racial disparities persist across the life course.For instance, nonwhite respondents acrossall three points in timeare, on average, nearly four times more likely than whites to live in a household in which the head was unmarried and unemployed. They arealso considerably more likely to live in households that received public assistance and less likely to live in an owner-occupied residence compared to white respondents at each of the three cross-sections. Some of the most notable racial differences, however, concern the level of neighborhood poverty to which nonwhite versus white respondents are exposed.Although the average poverty rates experienced by residents in low-, moderate-, and high-poverty neighborhoods are fairly similar for white and nonwhite respondents, often within just one to three percentage points of each other (results not shown but available upon request), exposure to high-poverty neighborhoods is a far more common and persistent phenomenon for nonwhite versus white young people. At age four, for example, only 11 percent of nonwhite respondents resided in low-poverty neighborhoods compared to nearly two-thirds of white respondents. This disparity is reversed at the less affluent end of the neighborhood poverty spectrum. That is, 64 percentof nonwhite four-year-olds were exposed to high-poverty neighborhoods compared to just eight percent of white four-year-olds. Although slightly smaller percentages of nonwhite respondents were exposed to high-poverty neighborhoods at ages 12 and 17 than at age four, the racial gap in exposure to neighborhood poverty remained largely intact acrossall three cross-sectionalassessments.

\section{[TABLE 2 HERE]}

Similar to a life table, Table 3 summarizesthe occurrence and risk of smoking initiation by age 25 ,as well as the more general trajectories of sample members from one year post-baseline (age five) through the administrative end of follow-up, including censoring not due to smoking onset,by age and race.In general, the probability of initiating smoking among all respondents is very low through age 11 , though the risk among nonwhite respondents is smaller compared to their white counterparts at almost every age. At age 14 , for example, the estimated probability of smoking onset is 0.01 for nonwhites and 0.03 for whites. Smoking risk peaks at age 18 for all respondents with an estimated probability of 0.09 for nonwhites and 0.13 for whites, 
suggesting that the minimum age to legally purchase cigarettes likely influences their uptake. Overall, 192 nonwhite and 486 white respondents, or 24 percent and 37 percent, respectively, began smoking by age 25 . Such findings align with prior research documenting lower prevalence of smoking among nonwhite, predominantly African American, youth and young adults.

However, as shownmore clearly in Figure 1, which depicts the probability of smoking initiationby age and race among respondents still at risk (i.e., those who had not already begun smoking at a younger age or who were never nonresponse), nonwhitesbegan to take up smoking at higher rates than whites at age 21 and continued to do sothrough age 25 . Such a notable crossover in the race-specific risk of smoking onset is also consistent with previous findings in the literature, which tend to show that nonwhites, particularly African Americans, start smoking later than whites, typically in their early twenties during the transition from adolescence to young adulthood(King, 1997; Malmstadt et al., 2001; Richardson, 1997). Although informative for preliminary assessments of racial disparities in smoking onset over the early life course, such summary statisticsprovide limited insight into the effects of neighborhood povertyor other time-varying and time-invariant covariates.

\section{[TABLE 3 HERE]}

[FIGURE 1 HERE]

\subsection{CumUlative NeighboRHood EfFECtS On SMOKING INITIATION}

Tables 4a and 4b present unadjusted (Model 1), IPT-weighted (Model 2), and conventional regressionadjusted (Model 3) estimates from race-specific discrete-time analyses of the risk of smoking initiation by age 25 as a function of the cumulative proportion of time respondentsspent in moderate- and high-poverty neighborhoods relative to low-poverty neighborhoods. The unadjusted models, which simply includethe neighborhood poverty variable and the quadratic function of age,indicate that the odds of smoking initiation increase as respondents get older, but decelerate during the later years among both nonwhite and white respondents (as indicated by the age and age-squared terms, respectively). With respect to neighborhood poverty, white respondents who experience more prolonged exposure to moderate- versus low-poverty neighborhoods have 33 percent greater odds $(p<0.10)$ while those who spend more time in high- versus lowpoverty neighborhoods have166 percent (or more than 2.5 times) greater odds $(p<0.001)$ of smoking initiation by age 25 , although only the effect of high-poverty neighborhoods reaches statistical significance at greater than the 95 percent confidence level (Table 4b).Among nonwhite respondents, however, there are no 
statistically significant effects on smoking initiation of more sustained exposure to either moderate- or highpoverty neighborhoods compared to low-poverty neighborhoods, although the effect of high-poverty neighborhoods is moderately significant at the 90 percent confidence level $(p<0.10$; Table 4a).

[TABLES 4a \& 4b HERE]

The IPT-weighted estimates in Model 2 adjust for selection into neighborhoods characterized by different levels of poverty as well as for time-invariant covariates measured at birth or the start of follow-up.Even after adjusting for such a host of individual and household characteristics, these estimates indicatethat among white respondents, the odds of smoking initiation increase by 72 percent $(p<0.05)$ with more prolonged exposure to high- as opposed to low-poverty neighborhoods (Table 4b). Among nonwhite, predominantly African American, respondents, the IPT-weighted estimates indicate no statistically significant association between the duration of exposure to more impoverished neighborhoods and smoking initiation (Table 4a). Overall, findings suggest that more sustained residence in a high- versus low-poverty neighborhood is associated with smoking initiation by age 25, even after accounting for individual- and household-level factors known to affect selection into neighborhoods; however, this association is only evident among white and not nonwhite respondents. Duration of exposure to neighborhood poverty, therefore, does not appear to alter the substantive conclusions of prior cross-sectional studies in which the association between neighborhood poverty and smoking behavior is evidentin white but not nonwhite youth and young adults. Moreover, when the IPT-weighted estimates are compared to the conventional regression-adjusted estimates in Model 3, which condition on time-invariant covariates as well as all time-varying covariates averaged across thefollow-up period, the IPT-weighted estimates of the effect of cumulative neighborhood poverty are slightly attenuatedfor both nonwhite and white respondents. This suggests that respondents' differential selection into more or less impoverished neighborhoods, as well as individual- and householdlevel factors,may in fact account for some of the effects on smoking behavior of neighborhood disadvantage that have been reported in prior research.

\section{DISCUSSION AND CONCLUSIONS}

This study examined the effects of more prolonged exposure to neighborhoods characterized by varying levels of poverty on the risk of smoking initiation by age 25 utilizing the 1970 to 2011 waves of the PSID merged with census data on respondents' neighborhoods. Two primary conclusions emerge from this investigation. First, the overall risk of early smoking initiation is lower among nonwhite compared to white 
youth and young adults despite higher rates of exposure to adverse socioeconomic characteristics at the individual, household, and neighborhood levels. Second, residing in a high- compared to a low-poverty neighborhood for repeated or prolonged periods of time is associated with early smoking initiation among white but not nonwhite respondents. More specifically, among whites, more sustained exposure to neighborhoodsin which more than 20 percent of residents are in poverty is related to a 72 percent increase in the odds of smoking onset before age 25 compared to more prolonged residence in neighborhoods with less than 10 percent poverty rates. Whereas the majority of prior scholarship on smoking behavior generally, and age at smoking initiation more specifically, has characterized the residential environment at only one time point, the estimates presented here are based on a duration-sensitive measure of respondents' neighborhoods from age four onwards, as well as relatively novel statistical methods that account for dynamic individual- and household-level factors known to predict future smoking behavior but which are also related to the differential selectionof families into and out of neighborhoods over time. As such, they provide among the strongest evidence for neighborhood effectson smoking initiationamong white youth and young adults, over and above the influence of individual- and household-level risk and protective factors.

However, consistent with prior research on smoking behavior, no statistically significant neighborhood effects were found among nonwhite respondents. Nonwhite respondents who grew up in predominantly highpoverty neighborhoods were no more likely than those who spent most of their yearsin low-poverty areas to initiate smoking byage 25 . Such an absence of an effect, especially in light of the statistically significant findings among white respondents, is particularly striking given dramatic racial disparities in exposure to neighborhood poverty throughout the child, adolescent, and young adultlife course. Nonwhite, predominantly African American, young people at every age were often as much as eight times more likely to reside in highpoverty neighborhoods compared to their white counterparts. Nevertheless, overall smoking rates were consistently lower among nonwhite respondents and age at initiation was unrelated to the poverty rate of the neighborhoods to which they were persistently exposed. Whereas a lack of attention to the temporal aspects of neighborhood exposures has been cited as a possible reason for null findings in the broader neighborhood effects literature (Wodtke, 2013; Wodtke et al., 2011), quantifying the duration of exposure to neighborhood poverty among nonwhite respondents does not appear to alter the substantive conclusions of smokingrelated studies that have relied on cross-sectional data. 
Future research in this area should more fully investigate the social and structural conditions and antismoking strategies operating in low-income communities of colorthat appear to buffer the effects of adverse neighborhood characteristics.As noted previously, the greater strength and prominence of anti-smoking norms among nonwhite, especially African American, residents have been posited as possible explanations for the lack of a neighborhood poverty-smoking effect among nonwhite young people. However, supplementary analyses controlling for the proportion of nonwhite residents in a neighborhood, as a proxy for the salience of such norms, have little substantive impact on the results presented hereforeither nonwhite or white young people (Appendix B). Prior scholarship suggests, however, that a shift in the prevalence of smoking occurs among adults over age 24 such that rates for nonwhites overtake those for whites(White et al., 2004), consistent with the racial crossover in smoking onset at age 21 that was observed here. Thus, the effects on smoking of adverse neighborhood characteristics may not manifest until later in the life course among nonwhite populations when family-level protective factors become less influential relative to neighborhood characteristics and the accumulation (or, as the case may be, the lack thereof) of concomitant resources and opportunities for success and mobility. The conventional assumption that most adult smokers report their first use by age 25 has been largely based on samples comprised primarily of whites (White et al., 2004). The results presented here challenge the generalizability of such claims, and highlight the value for neighborhood effects research more broadly of taking seriously the notion that the timing of residential exposures matters, not only in general but perhaps differentially by health outcome and race. Future studies investigating not only the duration, but also the timing of exposure to neighborhood poverty in diverse populations and for various health-related outcomes is recommended.

Although this study uses panel data and unique statistical methods to address some of the most common challenges in neighborhood effects research (namely, reverse causation and neighborhood selection bias), the results should be considered in the context of several remaining limitations. First, analyses are based on an analytic sample that that is further limited, given the historical timing of the PSID, to an aggregate "nonwhite" category (consisting of predominantly African American respondents) and a white category. Additional research examining smoking behavior as a function of cumulative neighborhood effects among Asian and Latino populations is encouraged. Second, this research was based on retrospective selfreports of age at smoking initiation, which can be unreliable. However, in one of the only studies to evaluate race differentials in the retrospective reporting of smoking onset, Johnson and Schultz (2005)document that 
whites but not African Americans tend to report events closer to the time of the interview than is true, a bias referred to as "forward telescoping". These findings suggest, therefore, that although recall bias (and forward telescoping in particular) remains a concern in this study, given the relatively early timeframe in which smoking onset is assessed, it likely contributes to conservative neighborhood effect estimates, as well as racial differences therein. Third, as alluded above, this study did not assess the specific social and behavioral mechanisms thought to differentially influence the race-specific associations observed between neighborhood poverty and smoking initiation. Longitudinal research able to more explicitly measure these potential mechanisms including, for example, school context and quality, peer pressure, parenting practices, and associatedsociocultural norms and attitudes about smoking in relation to racial-spatial patterns of inequality, would be enlightening. The link between neighborhood poverty and school context and quality, in particular, warrants additional attention. Future research examining the importance of each of the various contexts in which young people typically operate, including schools, places of worship, extracurricular groups and the like, and their relative contribution to the overall effect of neighborhoodsis recommended. Finally, this study only assessed one aspect of the neighborhood environment: poverty. Although neighborhood poverty is often a good proxy for other aspects of structural disadvantage, such as greater tobacco retail density, future research that more explicitly measures smoking-related characteristics of the residential environment is necessary.

Nonetheless, findings from the present study support prior research indicating that nonwhite, predominantly African American, youth and young adults are less likely than whites to initiate smoking during most ofthe early life course. The fact that nearly onein four nonwhite and more than onein three white respondents in this study had started smoking byage 25 , however, underscores the continued importance of tobacco prevention programs that target multiple spheres of influence, from individuals and families to the neighborhood environment, although micro- and macro-level interventions, as well as the developmental timing of their implementation,may be more or less efficacious among different racial/ethnic groups. Moreover, the results of this study should be interpreted in the context of long-term trends in adolescent and young adult smoking, which generally show a steep decline and then a leveling off from the mid-1970s through the early 1990s, followed by a sharp increase through most of the 1990 s and then another dramatic drop through the early 2000 s(Nelson et al., 2008). Although this study included at least some respondents who came of age during all four of these decades, the majority did sofrom the 1970s through the early 1990 s 
and the factors influencing smoking initiation then may be different than today. As other scholars have noted, however, given the decidedly nonlinear trend in adolescent and young adult smoking over the last 30 to 40 years and the tobacco industry's aptitude for adapting to and counteracting tobacco prevention strategies(Nelson et al., 2008), there is reason for continued concern and value to revisiting the determinants of smoking, including neighborhood poverty, across cohorts and throughout time. More generally and viewed in light of additional work by the author showing that children and youth who experience more prolonged exposure to neighborhood disadvantage are more likely to report worse self-rated health and to be obese as young adults, the findings from this study, although limited to white respondents, further highlight the importance of prior neighborhood context (and inequalities therein) for health and health behavior later in life. 


\section{REFERENCES}

Ahern, J., \& Galea, S. (2011). Collective Efficacy and Major Depression in Urban Neighborhoods. American journal of epidemiology, 173, 1453-1462.

Auchincloss, A.H., Diez Roux, A.V., Dvonch, J.T., Brown, P.L., Barr, R.G., Daviglus, M.L., et al. (2008). Associations between recent exposure to ambient fine particulate matter and blood pressure in the Multi-Ethnic Study of Atherosclerosis (MESA). Environmental Health Perspectives, 116, 486.

Beard, J.R., Cerda, M., Blaney, S., Ahem, J., Vlahov, D., \& Galea, S. (2009). Neighborhood Characteristics and Change in Depressive Symptoms Among Older Residents of New York City. American Journal of Public Health, 99, 1308-1314.

Centers for Disease Control and Prevention. (2011a). Tobacco Use: Targeting the Nation's Leading Killer at a Glance 2011.

Centers for Disease Control and Prevention (2011b). Vital Signs: Current Cigarette Smoking Among Adults Aged $\geq 18$ Years --- United States, 2005--2010. MMWR, 60, 1207-1212.

Chaix, B., Guilbert, P., \& Chauvin, P. (2004). A multilevel analysis of tobacco use and tobacco consumption levels in France. The European Journal of Public Health, 14, 186-190.

Chen, P., \& Jacobson, K.C. (2012). Developmental trajectories of substance use from early adolescence to young adulthood: Gender and racial/ethnic differences. Journal of Adolescent Health, 50, 154-163.

Chuang, Y.C., Cubbin, C., Ahn, D., \& Winkleby, M.A. (2005). Effects of neighbourhood socioeconomic status and convenience store concentration on individual level smoking. Journal of Epidemiology and Community Health, 59, 568-573.

Crowder, K., \& Downey, L.C. (2010). Inter-neighborhood migration, race, and environmental hazards: modeling micro-level processes of environmental inequality. American Journal of Sociology, 115, 1110-1149.

Cutrona, C.E., Wallace, G., \& Wesner, K.A. (2006). Neighborhood Characteristics and Depression: An Examination of Stress Processes. Current Directions in Psychological Science, 15, 188-192.

Diez Roux, A.V., \& Mair, C. (2010). Neighborhoods and health. Annals of the New York Academy of Sciences, 1186, 125-145.

Diez Roux, A.V., Merkin, S.S., Arnett, D., Chambless, L., Massing, M., Nieto, F.J., et al. (2001). Neighborhood of residence and incidence of coronary heart disease. New England Journal of Medicine, 345, 99-106.

Diez Roux, A.V., Merkin, S.S., Hannan, P., Jacobs, D.R., \& Kiefe, C.I. (2003a). Area Characteristics, Individual-Level Socioeconomic Indicators, and Smoking in Young Adults: The Coronary Artery Disease Risk Development in Young Adults Study. American journal of epidemiology, 157, 315-326.

Diez Roux, A.V., Merkin, S.S., Hannan, P., Jacobs, D.R., \& Kiefe, C.I. (2003b). Area characteristics, individual-level socioeconomic indicators, and smoking in young adults: the coronary artery disease risk development in young adults study. Am J Epidemiol, 157, 315-326.

Diez Roux, A.V., Nieto, F.J., Muntaner, C., Tyroler, H.A., Comstock, G.W., Shahar, E., et al. (1997). Neighborhood environments and coronary heart disease: a multilevel analysis. American journal of epidemiology, 146, 48-63.

Doubeni, C.A., Schootman, M., Major, J.M., Torres Stone, R.A., Laiyemo, A.O., Park, Y., et al. (2012). Health Status, Neighborhood Socioeconomic Context, and Premature Mortality in the United States: The National Institutes of Health - AARP Diet and Health Study. American Journal of Public Health, 102, 680-688.

Edelen, M.O., Tucker, J.S., \& Ellickson, P.L. (2007). A discrete time hazards model of smoking initiation among West Coast youth from age 5 to 23. Prev Med, 44, 52-54.

Ellickson, P.L., Orlando, M., Tucker, J.S., \& Klein, D.J. (2004). From Adolescence to Young Adulthood: Racial/Ethnic Disparities in Smoking. American Journal of Public Health, 94, 293-299.

Ellickson, P.L., Tucker, J.S., \& Klein, D.J. (2001). High-risk behaviors associated with early smoking: results from a 5-year follow-up. Journal of Adolescent Health, 28, 465-473.

Ennett, S.T., Flewelling, R.L., Lindrooth, R.C., \& Norton, E.C. (1997). School and Neighborhood Characteristics Associated with School Rates of Alcohol, Cigarette, and Marijuana Use. Journal of Health and Social Behavior, 38, 55-71.

Everett, S.A., Warren, C.W., Sharp, D., Kann, L., Husten, C.G., \& Crossett, L.S. (1999). Initiation of Cigarette Smoking and Subsequent Smoking Behavior among U.S. High School Students. Preventive Medicine, 29, 327-333. 
Flay, B.R., Hu, F.B., Siddiqui, O., Day, L.E., Hedeker, D., Petraitis, J., et al. (1994). Differential influence of parental smoking and friends' smoking on adolescent initiation and escalation of smoking. $J$ Health Soc Behav, 35, 248-265.

Frohlich, K.L., Potvin, L., Chabot, P., \& Corin, E. (2002). A theoretical and empirical analysis of context: neighbourhoods, smoking and youth. Soc Sci Med, 54, 1401-1417.

Gapen, M., Cross, D., Ortigo, K., Graham, A., Johnson, E., Evces, M., et al. (2011). Perceived Neighborhood Disorder, Community Cohesion, and PTSD Symptoms Among Low-Income African Americans in an Urban Health Setting. American Journal of Orthopsychiatry, 81, 31-37.

Gardiner, P.S. (2001). African American teen cigarette smoking: a review. Smoking and Tobacco Control Monograph No. 2: Changing adolescent smoking prevalence: where it is and why. Bethesda, MD: U.S. Department of Health and Human Services, Public Health Service, National Institutes of Health.

Gordon-Larsen, P., Nelson, M.C., Page, P., \& Popkin, B.M. (2006). Inequality in the Built Environment Underlies Key Health Disparities in Physical Activity and Obesity. Pediatrics, 117, 417-424.

Graber, J.A., \& Gunn, J.B. (1999). Developmental transitions: Linking human development with tobacco prevention research. Nicotine \& Tobacco Research, 1, S73-S77.

Griesler, P.C., \& Kandel, D.B. (1998). Ethnic differences in correlates of adolescent cigarette smoking. J Adolesc Health, 23, 167-180.

Hammond, D. (2005). Smoking behaviour among young adults: beyond youth prevention. Tobacco Control, $14,181-185$.

Harding, D.J. (2009). Violence, Older Peers, and the Socialization of Adolescent Boys in Disadvantaged Neighborhoods. American Sociological Review, 74, 445-464.

Jackson, J.S., Knight, K.M., \& Rafferty, J.A. (2010). Race and Unhealthy Behaviors: Chronic Stress, the HPA Axis, and Physical and Mental Health Disparities Over the Life Course. American Journal of Public Health, 100, 933-939.

Jencks, C., \& Mayer, S. (1990). The Social Consequences of Growing Up in a Poor Neighborhood. Inner-city poverty in the United States, 111.

John, R., Cheney, M.K., \& Azad, M.R. (2009). Point-of-sale marketing of tobacco products: Taking advantage of the socially disadvantaged? Journal of Health Care for the Poor and Underserved, 20, 489-506.

Johnson, E.O., \& Schultz, L. (2005). Forward telescoping bias in reported age of onset: an example from cigarette smoking. International Journal of Methods in Psychiatric Research, 14, 119-129.

King, G. (1997). The "race" concept in smoking: a review of the research on African Americans. Social Science \& Medicine, 45, 1075-1087.

Kleinschmidt, I., Hills, M., \& Elliott, P. (1995). Smoking behaviour can be predicted by neighbourhood deprivation measures. Journal of Epidemiology and Community Health, 49, S72-S77.

Lando, H.A., Thai, D.T., Murray, D.M., Robinson, L.A., Jeffery, R.W., Sherwood, N.E., et al. (1999). Age of initiation, smoking patterns, and risk in a population of working adults. Prev Med, 29, 590-598.

Lee, R.E., \& Cubbin, C. (2002). Neighborhood context and youth cardiovascular health behaviors. American Journal of Public Health, 92, 428-436.

Macintyre, S., Ellaway, A., \& Cummins, S. (2002). Place effects on health: how can we conceptualise, operationalise and measure them? Social Science \& Medicine, 55, 125-139.

Malmstadt, J.R., Nordstrom, D.L., Carty, D.C., Christiansen, A.L., Chudy, N.E., Rumm, P.D., et al. (2001). Cigarette smoking in Wisconsin: the influence of race, ethnicity, and socioeconomics. WMJMADISON-, 100, 29-33.

Matthews, S.A. (2011). Spatial polygamy and the heterogeneity of place: studying people and place via egocentric methods. In L.M. Burton, S.P. Kemp, M. Leung, S.A. Matthews, \& D.T. Takeuchi (Eds.), Communities, Neighborhoods, and Health: Expanding the Boundaries of Place. New York: Springer.

Miles, R. (2006). Neighborhood disorder and smoking: findings of a European urban survey. Soc Sci Med, 63, 2464-2475.

Mujahid, M.S., Diez Roux, A.V., Shen, M., Gowda, D., Sanchez, B., Shea, S., et al. (2008). Relation between neighborhood environments and obesity in the Multi-Ethnic Study of Atherosclerosis. Am J Epidemiol, 167, 1349-1357.

Nelson, D.E., Mowery, P., Asman, K., Pederson, L.L., O'Malley, P.M., Malarcher, A., et al. (2008). LongTerm Trends in Adolescent and Young Adult Smoking in the United States: Metapatterns and Implications. American Journal of Public Health, 98, 905-915.

Nowlin, P.R., \& Colder, C.R. (2007). The role of ethnicity and neighborhood poverty on the relationship between parenting and adolescent cigarette use. Nicotine and Tobacco Research, 9, 545-556. 
Papas, M.A., Alberg, A.J., Ewing, R., Helzlsouer, K.J., Gary, T.L., \& Klassen, A.C. (2007). The built environment and obesity. Epidemiologic reviews, 29, 129-143.

Quillian, L. (2003). How Long are Exposures to Poor Neighborhoods? The Long-Term Dynamics of Entry and Exit from Poor Neighborhoods. Population Research and Policy Review, 22, 221-249.

Reardon, S.F., Brennan, R.T., \& Buka, S.L. (2002). Estimating Multi-Level Discrete-Time Hazard Models Using Cross-Sectional Data: Neighborhood Effects on the Onset of Adolescent Cigarette Use. Multivariate Behavioral Research, 37, 297-330.

Reijneveld, S.A. (1998). The impact of individual and area characteristics on urban socioeconomic differences in health and smoking. International Journal of Epidemiology, 27, 33-40.

Richardson, T.L. (1997). African-American smokers and cancers of the lung and of the upper respiratory and digestive tracts. Is menthol part of the puzzle? Western journal of medicine, 166, 189.

Robins, J.M. (2000). Marginal structural models versus structural nested models as tools for causal inference. Statistical models in epidemiology, the environment, and clinical trials pp. 95-133): Springer.

Robins, J.M., Hernan, M.A., \& Brumback, B. (2000). Marginal Structural Models and Causal Inference in Epidemiology. Epidemiology, 11.

Sampson, R.J. (2013). THE PLACE OF CONTEXT: A THEORY AND STRATEGY FOR CRIMINOLOGY'S HARD PROBLEMS. Criminology, 51, 1-31.

Sampson, R.J., Raudenbush, S.W., \& Earls, F. (1997). Neighborhoods and Violent Crime: A Multilevel Study of Collective Efficacy. Science, 277, 918-924.

Sharkey, P. (2013). Stuck in place: Urban neighborhoods and the end of progress toward racial equality. Chicago: University of Chicago Press.

Sharkey, P., \& Faber, J.W. (2014). Where, When, Why, and For Whom Do Residential Contexts Matter? Moving Away from the Dichotomous Understanding of Neighborhood Effects. Annual Review of Sociology, 40, 559-579.

Shohaimi, S., Luben, R., Wareham, N., Day, N., Bingham, S., Welch, A., et al. (2003). Residential area deprivation predicts smoking habit independently of individual educational level and occupational social class. A cross sectional study in the Norfolk cohort of the European Investigation into Cancer (EPIC-Norfolk). Journal of Epidemiology and Community Health, 57, 270-276.

Siahpush, M., Jones, P.R., Singh, G.K., Timsina, L.R., \& Martin, J. (2010). The association of tobacco marketing with median income and racial/ethnic characteristics of neighbourhoods in Omaha, Nebraska. Tobacco Control, 19, 256-258.

Small, M.L. (2006). Neighborhood Institutions as Resource Brokers: Childcare Centers, Interorganizational Ties, and Resource Access among the Poor. Social Problems, 53, 274-292.

Small, M.L., \& Newman, K. (2001). Urban Poverty after The Truly Disadvantaged: The Rediscovery of the Family, the Neighborhood, and Culture. Annual Review of Sociology, 27, 23-45.

South, S.J., \& Crowder, K. (1998). Avenues and Barriers to Residential Mobility among Single Mothers. Journal of Marriage and Family, 60, 866-877.

Timberlake, J.M. (2007). Racial and Ethnic Inequality in the Duration of Children's Exposure to Neighborhood Poverty and Affluence. Social Problems, 54, 319-342.

Tomey, K., Diez Roux, A.V., Clarke, P., \& Seeman, T. (2013). Associations between neighborhood characteristics and self-rated health: A cross-sectional investigation in the Multi-Ethnic Study of Atherosclerosis (MESA) cohort. Health \& Place, 24, 267-274.

Tseng, M., Yeatts, K., Millikan, R., \& Newman, B. (2001). Area-level characteristics and smoking in women. American Journal of Public Health, 91, 1847-1850.

U.S. Department of Health and Human Services. (2010). How Tobacco Smoke Causes Disease: The Biology and Behavioral Basis for Smoking-Attributable Disease: A Report of the Surgeon General. Atlanta, GA: U.S. Department of Health and Human Services, Centers for Disease Control and Prevention, National Center for Chronic Disease Prevention and Health Promotion, Office on Smoking and Health.

Unger, J.B., Rohrbach, L.A., Cruz, T.B., Baezconde-Garbanati, L., Palmer, P.H., Johnson, C.A., et al. (2001). Ethnic variation in peer influences on adolescent smoking. Nicotine \& Tobacco Research, 3, 167176.

Welch, C., Bartlett, J., \& Petersen, I. (2013). Application of multiple imputation using the two-fold fully conditional specification algorithm in longitudinal clinical data. The Stata Journal.

White, H.R., Nagin, D., Replogle, E., \& Stouthamer-Loeber, M. (2004). Racial differences in trajectories of cigarette use. Drug and Alcohol Dependence, 76, 219-227. 
Wilson, W.J. (1987). The Truly Disadvantaged: The Inner City, the Underclass, and Public Policy: University of Chicago Press.

Wodtke, G.T. (2013). Duration and Timing of Exposure to Neighborhood Poverty and the Risk of Adolescent Parenthood. Demography, 50, 1765-1788.

Wodtke, G.T., Harding, D.J., \& Elwert, F. (2011). Neighborhood Effects in Temporal Perspective: The Impact of Long-Term Exposure to Concentrated Disadvantage on High School Graduation. American Sociological Review, 76, 713-736.

Xue, Y., Zimmerman, M.A., \& Caldwell, C.H. (2007). Neighborhood residence and cigarette smoking among urban youths: The protective role of prosocial activities. American Journal of Public Health, 97, 18651872.

Yen, I.H., \& Kaplan, G.A. (1999). Poverty area residence and changes in depression and perceived health status: evidence from the Alameda County Study. International Journal of Epidemiology, 28, 90-94. 
Table 1. Time-invariant sample characteristics by race

\begin{tabular}{|c|c|c|}
\hline & Nonwhite & White \\
\hline & $(n=808)$ & $(n=1,313)$ \\
\hline \multicolumn{3}{|l|}{ Gender, percent } \\
\hline Female & 50.62 & 50.27 \\
\hline Male & 49.38 & 49.73 \\
\hline \multicolumn{3}{|l|}{ Birthweight, percent } \\
\hline Less than 88 ounces & 10.64 & 4.80 \\
\hline 88 ounces or more & 89.36 & 95.20 \\
\hline \multicolumn{3}{|c|}{ Mother's marital status at birth, percent } \\
\hline Unmarried & 50.99 & 7.77 \\
\hline Married & 49.01 & 92.23 \\
\hline \multicolumn{3}{|c|}{ Household head's educational attainment at birth, percent } \\
\hline Less than high school & 42.82 & 13.71 \\
\hline High school graduate & 37.62 & 31.84 \\
\hline At least some college & 19.55 & 54.46 \\
\hline Mother's age at birth, mean (SD) & $23.45(5.39)$ & $26.11(5.00)$ \\
\hline
\end{tabular}

Note: Statistics reported for the first of five imputation datasets. 


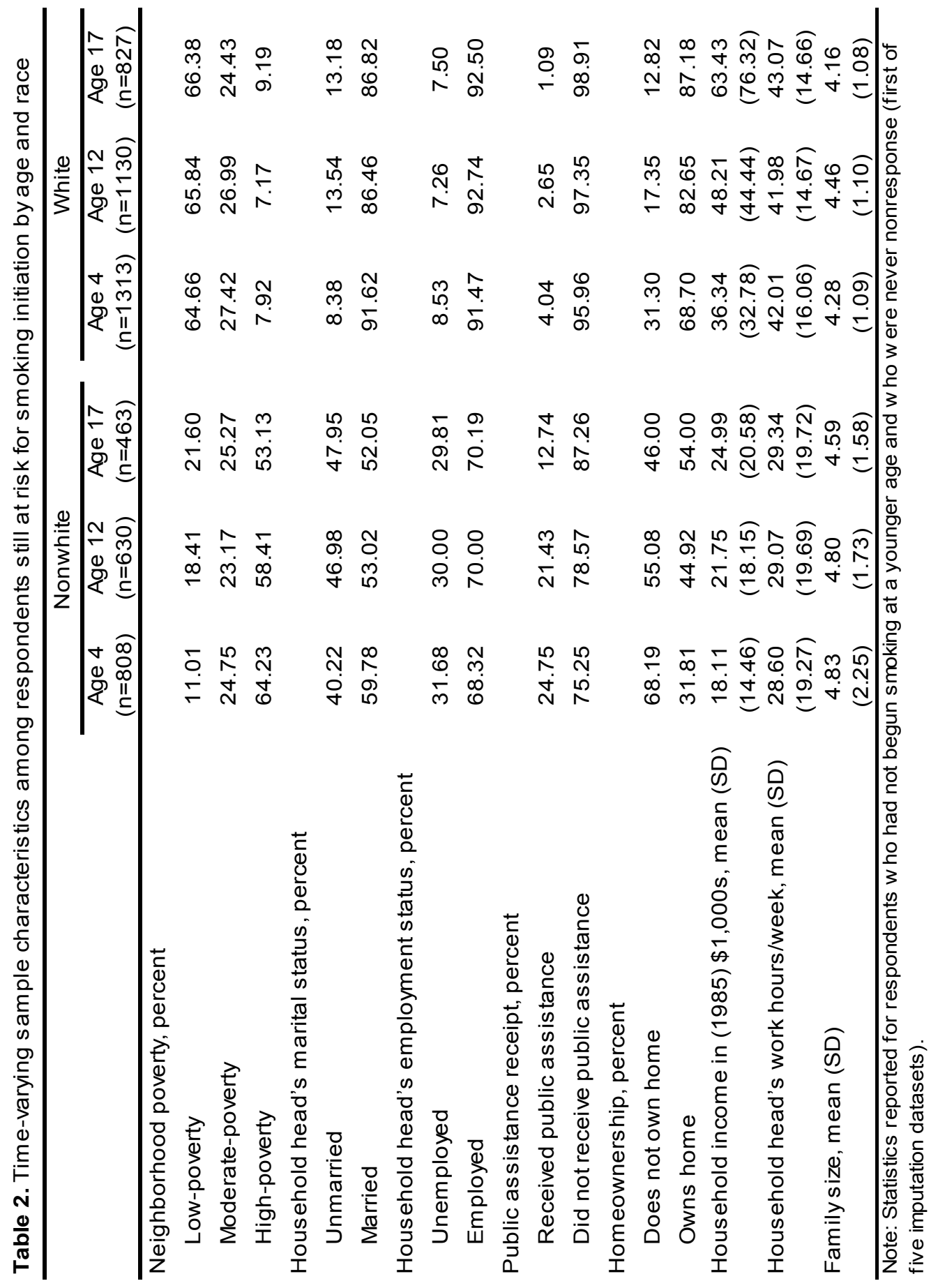




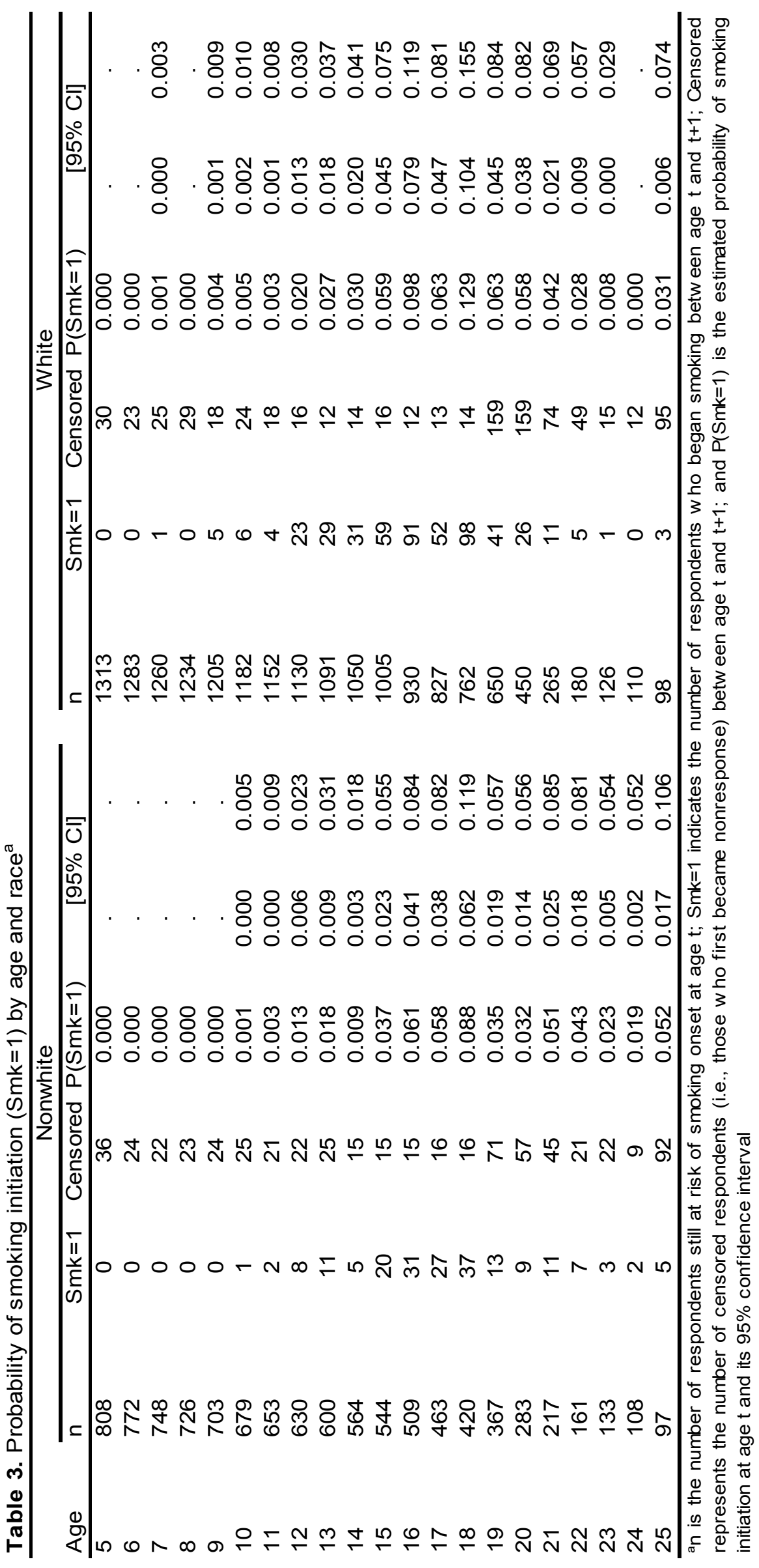




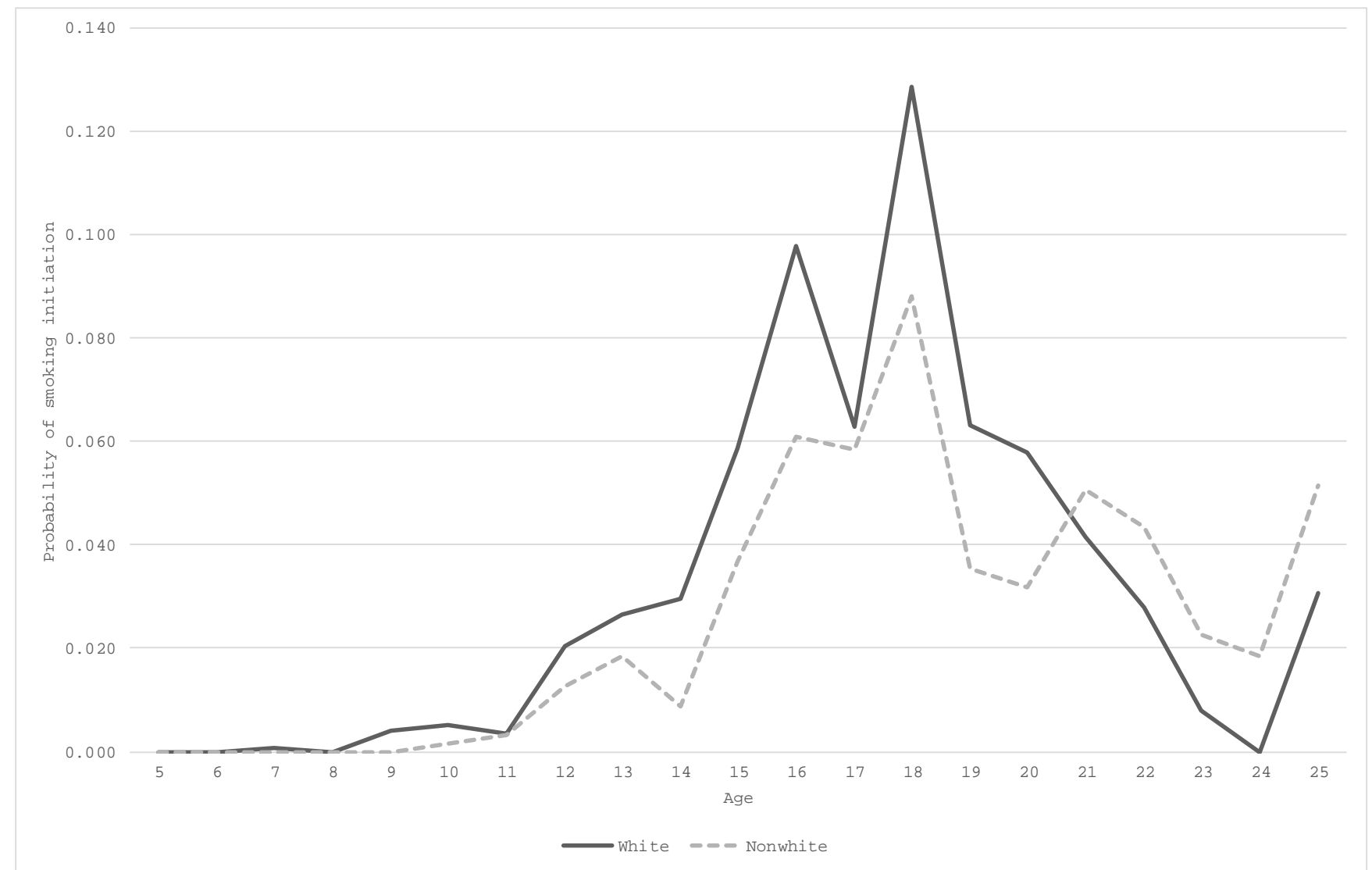

Figure 1. Age-specific probability of smoking initiation by raceamong respondents still at risk 
Table 4a. Discrete-time logit models for the effects of neighborhood poverty on the risk of smoking initiation by age 25 among nonw hite respondents $(n=10,185)$

\begin{tabular}{|c|c|c|c|c|c|c|c|c|c|}
\hline \multirow[b]{4}{*}{$\mathrm{NH}$ poverty, cumulative proportion (low } & \multicolumn{3}{|c|}{ Model 1} & \multicolumn{2}{|r|}{ Model 2} & \multicolumn{4}{|c|}{ Model 3} \\
\hline & \multicolumn{3}{|c|}{ Unadjusted } & \multicolumn{2}{|c|}{ IPT-Weighted } & \multicolumn{4}{|c|}{ Regression } \\
\hline & OR & \multicolumn{2}{|l|}{$95 \% \mathrm{Cl}$} & OR & \multicolumn{2}{|l|}{$95 \% \mathrm{Cl}$} & OR & \multicolumn{2}{|l|}{$95 \% \mathrm{Cl}$} \\
\hline & & & & & & & & & \\
\hline Moderate & 1.19 & $0.58-2.45$ & & 1.05 & $0.37-2.96$ & & 1.34 & $0.58-3.13$ & \\
\hline High & 1.59 & $0.92-2.73$ & * & 1.46 & $0.58-3.67$ & & 1.51 & $0.72-3.19$ & \\
\hline Age & 5.37 & $3.61-7.99$ & $* * *$ & 5.55 & $3.35-9.18$ & *** & 5.46 & $3.65-8.17$ & *** \\
\hline Age squared & 0.96 & $0.95-0.97$ & $* * *$ & 0.96 & $0.94-0.97$ & $* * *$ & 0.96 & $0.95-0.97$ & *** \\
\hline \multicolumn{10}{|l|}{ Gender (male) } \\
\hline Female & & & & 0.77 & $0.54-1.08$ & & 0.68 & $0.50-0.92$ & ** \\
\hline \multicolumn{10}{|l|}{ Birthw eight (88 ounces or more) } \\
\hline Less than 88 ounces & & & & 0.81 & $0.40-1.63$ & & 0.78 & $0.41-1.45$ & \\
\hline \multicolumn{10}{|l|}{ Mother's marital status at birth (married) } \\
\hline Unmarried & & & & 0.89 & $0.58-1.38$ & & 0.91 & $0.60-1.38$ & \\
\hline Mother's age at birth & & & & 1.01 & $0.97-1.06$ & & 1.01 & 0.98-1.05 & \\
\hline \multicolumn{10}{|l|}{ HH's education at age 4 (less than HS) } \\
\hline High school graduate & & & & 0.82 & $0.54-1.25$ & & 0.83 & $0.58-1.21$ & \\
\hline At least some college & & & & 0.86 & $0.50-1.48$ & & 0.87 & $0.54-1.39$ & \\
\hline \multicolumn{10}{|l|}{$\mathrm{NH}$ poverty at age 4 (low) } \\
\hline Moderate & & & & 1.01 & $0.42-2.45$ & & 0.90 & $0.45-1.79$ & \\
\hline High & & & & 1.15 & $0.49-2.74$ & & 1.07 & $0.55-2.07$ & \\
\hline \multicolumn{10}{|l|}{ HH's marital status at age 4 (married) } \\
\hline Unmarried & & & & 1.24 & $0.79-1.94$ & & 1.18 & $0.72-1.93$ & \\
\hline \multicolumn{10}{|c|}{ HH's employment status at age 4 (employed) } \\
\hline Unemployed & & & & 0.93 & $0.58-1.50$ & & 0.86 & $0.54-1.38$ & \\
\hline \multicolumn{10}{|l|}{ Homeow nership at age 4 (ow ns home) } \\
\hline Does not ow n home & & & & 1.34 & $0.88-2.06$ & & 1.13 & $0.72-1.80$ & \\
\hline Family size at age 4 & & & & 0.95 & $0.87-1.03$ & & 0.92 & $0.82-1.03$ & \\
\hline \multicolumn{10}{|l|}{ Public assistance receipt at age 4 (none) } \\
\hline Received public assistance & & & & 2.19 & $1.42-3.37$ & *** & 1.56 & $0.99-2.48$ & * \\
\hline Household income at age 4 & & & & 1.08 & $0.78-1.50$ & & 1.01 & $0.78-1.32$ & \\
\hline HH's w ork hours per w eek at age 4 & & & & 1.01 & $1.00-1.02$ & & 1.01 & $0.99-1.02$ & \\
\hline \multicolumn{10}{|l|}{ Year born (1966-1969) } \\
\hline 1970-1974 & & & & 0.72 & $0.37-1.42$ & & 0.76 & $0.45-1.27$ & \\
\hline $1975-1979$ & & & & 1.02 & $0.57-1.85$ & & 1.09 & $0.65-1.81$ & \\
\hline 1980-1984 & & & & 1.48 & $0.84-2.59$ & & 1.43 & $0.86-2.37$ & \\
\hline 1985-1989 & & & & 1.13 & $0.56-2.29$ & & 1.10 & $0.55-2.23$ & \\
\hline 1990-1993 & & & & 0.54 & $0.06-5.05$ & & 0.62 & $0.07-5.28$ & \\
\hline HH's marital status, average & & & & & & & 0.88 & $0.48-1.62$ & \\
\hline HH's employment status, average & & & & & & & 4.94 & $1.60-15.26$ & $* * *$ \\
\hline Homeow nership, average & & & & & & & 1.26 & $0.71-2.27$ & \\
\hline Family size, average & & & & & & & 1.04 & $0.90-1.21$ & \\
\hline Public assistance receipt, average & & & & & & & 1.12 & $0.52-2.40$ & \\
\hline Household income, average & & & & & & & 1.00 & $1.00-1.00$ & \\
\hline HH's w ork hours per w eek, average & & & & & & & 1.03 & $1.00-1.06$ & ** \\
\hline
\end{tabular}


Table 4b. Discrete-time logit models for the effects of neighborhood poverty on the risk of smoking initiation by age 25 among white respondents $(n=17,303)$

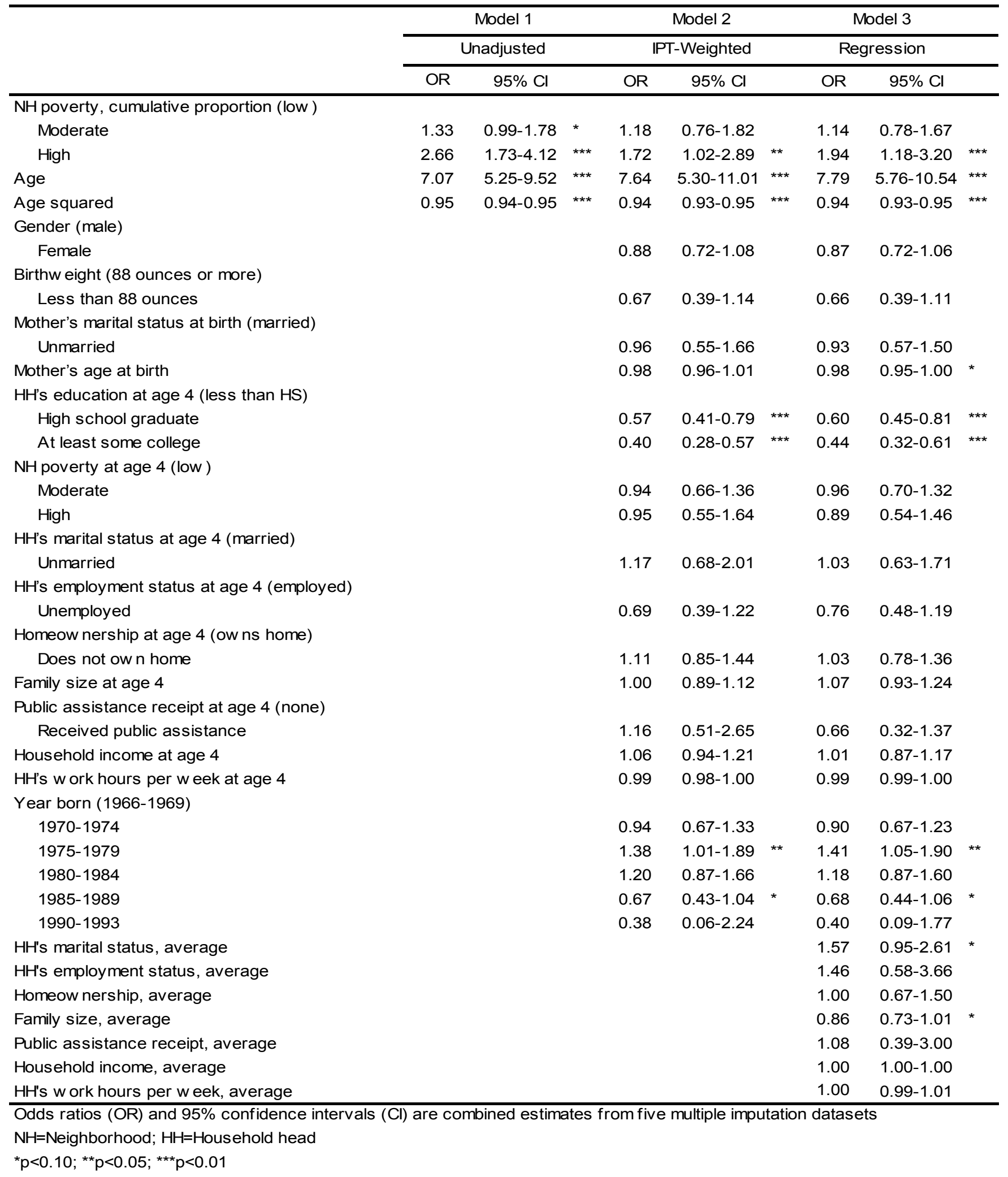

